T. Olson, Unpublished Doctoral Dissertation, University of Alberta, 1986.

Reviewed by

Marilyn A. Ray

University of Colorado

I could not theorize myself out of the pain and the hope, the life of illness. I stand in illness in my research before God, one of the world in pain and hope. I want to live in understanding. I want to learn how one ought to live through illness, even through the grief of pain. (pp. iv, v) ${ }^{1}$

Carol Olson's dissertation is one of awe, beauty, and mystery. One is struck by the artistry with which such a profound question as "How can we understand the life of illness?" is answered. By blending a hermeneutic-phenomenological approach using self-disclosed dialogue with illness and literary works of art, Olson arrives at understanding. Olson's understanding is a living through the answer, that is, knowledge of how we ought to live. In living through the answer, Olson is not, as Gadamer (Outhwaite, 1985) stressed, forgetting her own horizon of meaning; she is merging and fusing her own horizon with others in the process of the research. The research begins with the question, "How can we understand the life of illness?" and ends with mystery.

This review of the dissertation takes the form of a presentation of the research framework and synopsis of the text, a discussion of the emergence of themes, and an illumination of meaning.

\title{
Research Framework
}

The research framework for the study consists of many dimensions-self-questioning and dialoguing with illness, a hermeneutic-phenomenological investigation of literary works using interviewing and text interpretation, and reflection and writing. The phenomenological sense is both language and thoughtfulness to the phenomenon (lived experience), to what shows itself (van Manen, 1984, p. 41).

Olson's work is an enlightening journey. Although she claims that her research began with the concerns of the life of illness as experienced through the literary works of art, the first four Phenomenology + Pedagogy Volume 6 Number 3 
chapters of the dissertation also are a search - a mode of inquiry into her own experiences in coming to the question. She explores the following:

1. what is at stake in the research question -an exploration of contexts: critical, personal, linguistic, and purpose;

2. the question of understanding - an exploration of understanding by presenting hermeneutic-phenomenology as a way to understanding through dialoguing with the inner nature of experience and interpreting the language of illness;

3. the good of understanding - an exploration through a critique of traditional theories of professional health care and Heidegger's presentation of Verfall (a falling away from our self, p. 23); and

4. the how of understanding - an exploration of the pathway of wonder at what is: speech in the light of logos (caring) and being-toward-death. The exploration leads to an analysis of Kierkegaard's question and method in understanding faith as an example for the research question.

In the remaining chapters, Olson responds to her question by textual interpretation of literary works of art which speak to the experience of illness leading to a direct insight or unity of meaning of the whole of the experience of understanding a life of illness. The text evolves by means of interviewing a physician, chaplain, nurse, and her own mother who interpret the literary sources particularly relevant to their experience of illness. Each reveals more answers to the question of understanding. Using all these sources, Olson discovers major themes with which she titles each chapter. Minor themes which relate to the major themes are identified by side headings, marginal notes, and essay style responses. In this process, Olson employs the use of first and second reflective analyses. In the first reflection, a way of thinking about illness yields thematic statements which remain open to living thought. In the second reflection, identified thematic statements reveal the meaning of the experience of illness while evoking the uniqueness of individual experience so that each individual is "opened up" to new experiences (pp. 34-35). The research becomes the between (p. 35).

The final technique in the research process is a deeper reflective penetration into the phenomenon of illness by transcendental subjectivity (phenomenological reduction) (Natanson, 1973 , p. 124) to reveal or illuminate the truth of understanding a life (her life) of illness. Olson finds the answer to her search. 


\section{Synopsis of the Text}

In Chapters I and II, in exploring what is at stake in the research question and the question of understanding itself, Olson experiences the process of self-understanding. First, she proclaims how all humanity throughout history are children of technology (p. 1). From a personal standpoint, she points to her own life with illness and technology. Olson's life of illness is that of kidney failure, and her life is sustained by a kidney dialysis machine with frequent dialyzing treatments. Olson states that the journey through the years with a technological parent (the dialysis machine) is a human journey- "dependence on the machine, rebellion from the machine, oneness with the machine" (p. 2). A dialysis machine is a relationship-a relationship to self and others including doctors, nurses, family, and friends. But she further points out that her life in dialysis is not strictly a relationship with others; dialysis is a relationship with life itself (p. 2). Although bracketing technological certainty is stated as the starting point of the research and central to the mode inquiry for understanding, for Olson, technology is integral to her life. Technology is her. Thus technological certainty is Olson's horizon of meaning. (We see later how this idea is manifest in the fullness of how she understands her life of illness.)

Second, in her exploration of living a life of illness - of kidney failure which took the lives of her siblings, two brothers and three sisters, Olson's question of understanding illness and what she states is the more specific question, "How ought we to live through illness?" are presented as a challenge to those in the health care professions. Olson questions the meaning of authentic relationship for health care professionals. She discusses the responsibility for oneself and for the other. She especially highlights involvement for the well-being of a person based not only on behavioral implications of organic symptoms but also on mutual participation. The doctor and the patient share responsibility (p. 18). Olson asserts that the health care system is in crisis because of the failure of mutuality in professionals' interaction with patients. She says, "We have forgotten how to listen and to speak with each other" (p. 3).

To guide her, and ultimately the reader, to understand what has been forgotten, Olson's exploration of linguistic aspects of the question calls attention to two fundamental processes of relationship: speech, which is a moral responsibility of community members, and caring, the life force of community the ancient Greeks called logos. Both are intertwined. Olson remarks that the ancient Greek responsibility for community 
was presented in the image and in the activity of caring for the hearth which provided warmth and togetherness for the collective family - the community. Caring transformed the fire and those who tended, used, and shared it. Thus logos, the life force of caring, joins separate lives into a collective endeavor by calling each one to a personal commitment to care for the good of the other (pp. 3-4). The mystic Merton (1961) reminds us of the following:

Mere living alone does not isolate a man [woman], mere living together does not bring men [women] into communion. The common life can either make one more of a person or lese of a person, depending whether it is truly common life or merely life in a crowd. To live in communion, in genuine dialogue with others is absolutely necessary if man [woman] is to remain human. (p. 55)

Finally, Olson's search for understanding and challenge to the question of understanding itself are "to listen to another individual and to participate in the truth of what he or she says" (p. 13). Understanding is a community of shared meaning sustained by the integrity of the individual in conversation, the enabling of dialogue (p. 13). Thus, for Olson, "How can we understand the life of illness?" is another way of asking, "How can we dialogue with illness?" (p. 13).

In Chapters III and IV, an exploration of the good and the how of understanding prepares Olson for doing the specific research. The good of understanding is explored through theorizing as a way of asking, "How can we understand?" and by a critique of traditional theories of professional health care.

A theoretical example used in professional health care for approximately five decades emphasizes Parsons' case of illness as a functional analysis of social systems (p. 17). According to Parsons, care of the ill is a social role relationship aimed at returning a dysfunctional individual (the patient who is considered socially deviant) to a functional state by the physician whose technical qualifications grant him or her the power by diagnoses and treatment to accomplish this task (pp. 17-18).

In sharp contrast to the good of understanding of the experience of illness as a functional analysis of social systems, Olson reports two revolutionary experiments. Both theories seek the logos of the experience of illness in responsibility, that is, taking control of one's own illness. For example, Cousins, a physician, used laughter as a means to recovery in his own experience of illness. Mendelsohn, also a physician, advocated a new medicine: an ethical system made viable through family and community where the dominant ethic is regard for the 
rights and dignity of each human being (pp. 20-21). Olson concludes the chapter on the good of understanding by turning to Heidegger's theorizing in the journey to understand or the homecoming journey - "to come home to what is authentic" (p. 20). By discussing Heidegger's notion of Verfall (the falling away from self), or the being that is us, we can see how the individual can be eroded into commonality (pp. 22-23). What is important in Olson's description of the journey toward understanding is that in experiencing what is inauthentic, such as the erosion into commonality in society or the reduction of a personality to an official identity as Marcel claimed, there is a longing for what is authentic. Olson quotes Heidegger:

Desire and hope are the reaching-forward of care. Thus, care underlies and necessitates "the possibility of being full" (authentic). The careless man and the uncaring are not free. It is care that makes human existence meaningful, that makes a man's life signify. (p. 23)

Caring or logos is at the heart of community so that collective theyness is not inauthentic but authentic. The question of the good of understanding to Heidegger, therefore, is not adventure but homecoming where caring (logos) and authenticity are the guides.

In exploring the how of understanding in Chapter IV, Olson uses three rubrics of authenticity to guide her understanding of the homecoming journey: first, wonder at what is-the egsence of . truth; second, speech in light of logos using Heidegger's example of the artist as an open place for unconcealing and concealing being (Van Gogh's painting of peasant shoes); and third, a profound sense of death that wakes us up to life (Kierkegaard's journey in the Biblical account of the faith of Abraham, pp. 26-33). Thus, in the how of understanding, Olson sheds light on the subject matter itself-to allow it to be what it is by recognition of the researcher as artist, as spectator/theorist. Olson declares that the researcher as artist or spectator/theorist means "to re-search the temporal for what is 'lasting and true' in a way that transforms what is lasting and true "into an image or a form"' (p. 29). Human science research or the how of understanding is to speak the life of one who lives the truth of the subject matter (p. 29). Thus, for Olson, to understand the homecoming journey (to come home to what is authentic) is to understand the life of illness, the truth of the subject matter through the illumination of its meaning in the lives of friends, family, health care professionals, through literary works of art, including the life and being of Olson herself. 
Chapters V to X reveal the "essence of truth" in understanding the life of illness (pp. 35-36). In Chapters V to IX, Olson searches for her answer with her conversants (a physician, chaplain, nurse, and her mother) by describing and dialoguing with literary texts. Themes articulate shared understanding. Olson highlights that "themes reveal possibilities for living in this question until the themes themselves become open to deeper understanding" (p. v). Chapter X reveals the deepest understanding of all to Olson: her homecoming to what is authentic.

\section{Emergence of Themes}

"One Against the Other Searches for the Other" is a major theme that emerges when Olson searches with the help of a chaplain through Ivan's experience of dying in Tolstoy's The Death of Ivan Ilyich. The shared meanings reveal that Ivan had to let go of the things of lifo-his roles as husband, father, friend, judge, master, Catholic, and poker enthusiast to find the meaning of life. In his last moment of dying Ivan was transformed; "the 'It' that has pursued him is light" (p. 49). Ivan let go of the things that kept him away from home. Ivan had come home (p. 49). In his last moment, Ivan found joy and peace through suffering. Suffering became the place and time of his joy and peace (p. 52).

The major theme "One With the Other" emerges as Olson journeys with Pauline, a woman diagnosed as having a disease that slowly destroyed the arteries in her lungs causing heart disease, in the book Pauline's Diary. In Pauline's Diary, the theme of learning to be willing to die when life is loved so much illuminates meanings of the mystery of pain and the call to God, "Where are you?" (p. 56). In anguish is the nearness and instance of God. For Pauline, the omnipotence of God is this mystery as well as the image of Jesus, God's Son, dying on the cross (p. 56). Hope is the meaning. "The humility of hope is a response to the Infinite Being to whom one is conscious of owing everything.... Hope is stronger than death" (p. 60). Olson discovers that the grief of death is born as hope-reconciled to God, the giver of life, and the giver of life in death (p. 68).

The major theme "One for the Other" in Camus' novel The Plague is revealed through interviewing a Doctor of Medicine. In The Plague, Doctor Rieux, the narrator, is a citizen of Dian, France where the disease broke out. The gates to the city were closed to guard against its spread. The consciousness of community was inaugurated (pp. 71-73). Through this work, Olson 
and the doctor explore the meaning of illneses to a doctor when there is no technology to sustain life. Suffering becomes the meeting place where the doctor and the patient share the ache and the hope of all human existence. For the doctor and the patient "there is no cure now but there will be someday" ( $p$. 74). The doctor's heart is moved to pity-the devotion of care (p. 77). Although death occurs, it brings the challenge that the patient must not die in vain (p. 81). Thus, for scientific medicine, the illness and death of a person give life to science, and it is the devotion to care (the heart of pity) that gives science to life (p. 81).

Through the experience of nursing in Florence Nightingale's writing, Notes on Nursing, a nurse helps to reveal the theme "One by the Other"-to be there, a nurse, during illness. Through her life and writings, Nightingale exemplified the essence of care. Care is the Being of being there which Heidegger found as the essence of human experience (p. 84). The nurse is present to the patient. Presence is found in care, in silence, and in speech. Trust is the abiding as if as the condition for nursing care (p. 88). The nurse sponsors the mutual endeavor, the mutual accomplishment to stand with the patient against pain (p. 89), and when pain does not pass, the nurse in the presence of care gives hope, even love, and also mediates God's love (p. 90). In the shadow of pain and death, the nurse "gives from the heart and receives to the heart" (p. 90).

With the help of her mother (who experienced grief and loss in the illnesses and deaths of her five children and her husband), Olson journeys through Tennyson's poem In Memoriam, A.H.H. to develop the theme "One Without the Other." The poem journeys through the experience of grief, of not having the other when going through the confusion of grief and finally acceptance, peace, and even joy (p. 92). Grief is shared. "This expression of grief in words and tears gives release to the pain and anguish dwelling in the depths of our being" (p. 93). Olson and her mother ask the questions: "Is there not always hope and faith as in living with the memory of love? Can someone who was loved and needed ever really leave our lives?" (p. 95). Their answer is, "The life we shared is never lost though never found again" (p. 96).

In the final chapter, Olson reveals the theme "The Gathering." Through her hermeneutic-phenomenology and ultimately transcendental subjectivity, Olson is committed to search for understanding by an exploration of the question of understanding itself, in the authored texts, in the insights of conversants, and in her own direct apperception of the whole of the 
experience of illness. Olson "found life there" and from the textual language she surrounds it with writing that her own reflection reveals (p. 104). Olson has the care and assistance of her mentors (p. 109). Her thoughts and her writings are also a prayer. She refers to those thoughts as those that come from the heart of experience (called pain by Gadamer), the love that comes from God (p. 109). As a student of the research question, Olson ends with her description of what "the homecoming" is for her. Coming home to what is authentic is hope in the beginning of each new day, that hope in illness and death is the comfort of God's eternal love, embodied in the life of Jesus and in the lives of people who care (p. 110). In Olson's journey to the question, the answer is logos, the mystery understood through the depth of her Christian faith. The logos or life force (caring or love) is "the Word of God-Jesus to whom she gives her life" (p. 110).

Through Olson's work, one understands that there is ultimately Infinite Being at the root of our limited being. Faith in God through the embodiment of Jesus known through the Word and human beings who care are the keys to understanding. For Olson, faith is the final meaning of human existence, and the answer to the question of understanding the life of illness cannot be reached in any other way. Understanding is precisely in the recovery of our union with one another in Jesus. Thus Olson finds her understanding in Christian theology. The death and resurrection of Jesus with the imagery of the cross and empty tomb (p. 110) deepen Olson's awareness to the certitude of God's eternal love and dynamic intervention in her life. Olson's knowledge of God from her experience of His mercy through dialogue and reflection liberate her from total self-concern. She concludes, "And in the weariness and rigor of illness, we will learn to rest our souls like a child at home. We are children of God" (p. 110). Olson's final question, "How can we ever hope unless we can always hope?" is answered ( $p$. 110).

\section{Illumination of Meaning}

Olson's key interpretive and transcendent insight in a study of understanding the life of illness both from the historical and modern perspectives is that a life of illness cannot be understood except from the standpoint of caring and the presence of the divine reality from a Christian perspective. The life of illness is the arena for God's purposeful activity and a human being's creative potential. In Olson's understanding of a life of illness, the virtues of faith, hope, and love are paramount. As Martin (1987) stated, "Christian hope knows no limits because 
it is based on a relationship of love with God and 'there is no limit to love's forbearance, to its trust, its hope, its power to endure' (1 Corinthians 13:7)" (p. 28). Thus the ultimate meaning of Olson's understanding of Christian hope in illness is the awaiting of the coming of the Lord Jesus when humans will rise in the Lord to eternal glory. In the meantime, that waiting must make use of the abilities and gifts from the Lord in caring for and being cared for by others. Thus the focus is both human and divine.

Olson's insight has important implications for the health care delivery system as well as for human culture at large. For the health care system, it can be viewed as a health care theology similar to the way in which Maritain and Neibuhr speak of what politics should become, that is, a political theology where love is the mediating process (Cooper, 1985, pp. 3-6). Thus health care provision should be theologically based to understand the life of illness and suffering. ${ }^{2}$ Accordingly, a new health care system must include a view of God and a view of health and illness where not only curing but caring (love) is the means of and ends to practice. This view is not altogether new, however, in medicine and nursing. The theological view of health care has a long history (Numbers \& Amundsen, 1986). For example, Nightingale (1860) wrote: "Go your way straight to God's work in simplicity and singleness of heart" (p. 135). It is only in the contemporary era of professional health care delivery that caring for others has been redefined primarily as a science, and more recently as a business, an industry, or a technology.

Western society (which includes the health care system) assumes that care for persons and God are separate human concerns. Olson's research discredits that separation. Her direct insight of the meaning of the whole of the lived world of the experience of illness is the finding of the answer to her question in the name of logos - the Word of God, Jesus (p. 110). The Word, as Luther proclaimed, is "nothing but the proclamation of Christ, as found in the Gospel, which took place so that you can hear how your God speaks to you" (Hellerbrand, 1988, p. 7). The Word is expressed by Olson as hope: "My hope in illness and death is the comfort of my Creator's eternal love, embodied in the life of Jesus and in the lives of you who care" ( $p$. 110).

Olson underscores the need to recapture a synthesis between human culture and the Word of God and to recapture this need in the health care system today. 
A synthesis is outlined by Scarry in her work The Body in Pain. The Making and Unmaking of the World (1985). She presents as companion texts Judeo-Christianity and Marx's historical philosophy of materialism. Scarry suggests that the shared Judeo-Christian and Marxist's convictions of the "problem of suffering" takes place and must be understood within the frame of the "problem of creating" (p. 277). She remarks that "the nature of creation, however self-effacing, must be conceptually available and susceptible to description so that its overall structure or action can be recognized and repaired" (p. 325).

Olson's interpretation of the life of illness gives clues to the understanding of suffering and creation. She makes it conceptually available so that its structure and action can be recognized and repaired. In Olson's journey to understand suffering, human experience and faith are interconnected. However, the dialectic of opposites facilitates the understanding. A profound sense of pending death or death itself is used to describe and understand life such as Kierkegaard's biblical and existential account of the faith of Abraham, Olson's relationship with the kidney dialysis machine, and ultimately the cross of Christ. Interestingly, technology is a part of each of these descriptions. Although Olson says she bracketed technological certainty to find the answer to understanding illness, in her descriptions technology is a form of certainty to the whole of understanding itself. Through technology as well as with faith, God's presence is known in the world, giving further clues to the reality of a synthesis of human culture and the Word of God.

To explain this synthesis further, according to Scarry (1985), in the Old Testament through the Biblical account of the suffering and faith of Abraham, and in the New Testament through the suffering and death of Jesus, weapons or technology are used to describe and understand God's immediate interactions with humanity. Abraham's supreme test of faith was the quieting of the knife to be used to slay Isaac his son so that the descendants could be the inheritors of the promised land. Faith, in this example, came by being oneself wounded (Abraham's suffering a command to slay his son), and at the same time being the object of touch by God (Abraham's relinquishment by God to slay Isaac because of his total commitment to living in faith). In the New Testament, the cross is the weapon or technology whereby we see God's most intimate contact with humanity through His embodiment in Jesus. In Olson's journey to understanding a life of illness, ultimately, 
the Being to whom she can turn and who gives her faith and teaches her to live in faith is Jesus - the Word of God. God is manifest in Jesus on the cross. As Olson states, "I look to the cross and the empty tomb-the death and resurrection of Jesus" (p. 110). In Jesus, the body substantiates God. The cross (the technology) becomes self-substantiating. Human suffering is God's suffering as well. In short, it is through technology or the weapon that humanity and the Word of God meet.

For Olson, the technology of the kidney dialysis machine is like the cross of Jesus. The cross and the machine are the signs of life and hope, as well as suffering and death, in her journey of faith. Technology, thus, is not alien to understanding life but is and has always been central to substantiating God's presence in the world. Only the forms have changed. We are children of God, as Olson states (p. 110).

By being able to describe thoughts that came from the heart of experience as Olson does, which Gadamer called pain which refers to the love that comes from God (p. 109), the overall structure or action of a life of illness can be recognized. The effort to understand the problem of suffering can only be understood within the problem of creating, as Scarry's work illuminated. The technology (weapon) is the means by which the mystery of life and death are known. Life and death are found through technology, not against it. With this recognition, what is left to repair as Scarry (1985) puts it, is how we ought to live with technology. The need now is to understand morally how technology is both the object of suffering (wounding) and relief from suffering (touching or healing). This is the challenge of modern health care.

The contemporary health care system, thus, can become a health care theology. By understanding that life and death can be found in moral technology (and science), by understanding that love for one another in caring is the concrete sign of God's love, and by knowing that it is through faith that we understand the world as God's creation there can be a reconciliation of the estrangement between the human and the divine in the activities of service to the sick and needy. By her ways of being and knowing, Olson shows how faith and human experience are intertwined. Olson invites health care professionals and others to stand before God, to live in understanding, and to learn how we ought to live. 


\section{Notes}

1. References made without author are Olson's.

2. Olson speaks of Christian theology in understanding illness. A study of non-Christians would be needed to understand the life of illness from different theological or spiritual perspectives, for example, see Watson (1985).

\section{References}

Cooper, J.W. (1985). The theology of freedom. The legacy of Jacques Maritain and Reinhold Niebuhr. Macon, GA: Mercer University Press.

Hellerbrand, H. (1988). Martin Luther on Christian living. Weavings "Woven Together in Love": A Journal of the Christian Spiritual Life, 3(3), 6-13.

Martin, G. (1987). Hope. God's word today, 9(12), 28.

Merton, T. (1961). New seeds of contemplation. New York: New Directions.

Natanson, M. (1973). Edmund Husserl: Philosopher of infinite tasks. Evanston, IL: Northwestern University Preas.

Nightingale, F. (1860). Notes on nursing. New York: Appleton.

Numbers, R., \& Amundsen, D. (1986). Caring and curing: Health and medicine in the Western religious traditions. New York: Macmillan.

Outhwaite, W. (1985). Hans-Georg Gadamer. In O. Skinner (Ed.), The return of grand theory in the human sciences (pp. 21-39). New York: Cambridge University Press.

Scarry, E. (1985). The body in pain. The making and unmaking of the world. New York: Oxford University Press.

van Manen, M. (1984). Practicing phenomenological writing. Phenomenology + Pedagogy, 2(1), 31-69.

Watson, J. (1985). Nursing: Human science and human care. Norwalk, CN: Appleton-Century-Crofts. 